\title{
Analisis Kebijakan Fiskal dalam Perspektif Ekonomi Islam; Sebuah Kajian Historis Pada Masa Umar bin Khattab
}

\author{
Ferry Khusnul Mubarok \\ Fakultas Ekonomi dan Bisnis Islam UIN Walisongo Semarang \\ ferrykhusnulmubarok@walisongo.ac.id
}

\begin{abstract}
Fiscal policy in the Islamic period underwent various developments, both progress, and setbacks. Umar bin Khattab became one of the successful caliphs in the economic field, especially in managing his public finances. This article aims to identify fiscal policies in the time of the Caliph Umar bin Khattab, starting from the budget policy system, the financial management and allocation system, and its success. The method used is a qualitative approach. The data source used is secondary data with library research techniques, namely by collecting data derived from books, research results, websites, and other relevant sources. Analysis of data using descriptive technical analysis. The results of the discussion showed that fiscal policy during the Caliph Umar bin Khattab used a balanced budget system that was managed through Baitul Maal. Fiscal policy instruments developed include zakat, infaq, sedkah, wakaf, ghanimah, fa'i, kharaj, jizyah, ushur, and khums. Meanwhile, in terms of expenditure on budget allocation based on a priority scale, then it is used to fulfill the needs of mustahik, defense and security, social and religious, and state administration.
\end{abstract}

Keyword: Fiscal Policy Instruments, Umar bin Khattab, Islamic History, Public Finance

\begin{abstract}
Abstrak
Kebijakan fiskal di masa Islam mengalami berbagai perkembangan, baik kemajuan maupun kemunduran. Umar bin Khattab menjadi salah satu khalifah yang berhasil di bidang ekonomi, terutama dalam pengelolaan keuangan publiknya. Artikel ini bertujuan untuk mengidentifikasi kebijakan fiskal di masa Khalifah Umar bin Khattab, mulai dari sistem kebijakan anggaran, sistem pengelolaan dan alokasi keuangan, dan keberhasilannya. Metode yang digunakan adalah pendekatan kualitatif. Sumber data yang digunakan merupakan data sekunder dengan teknik library research, yaitu dengan mengumpulkan data yang berasal dari buku, hasil peneltian, website, dan sumber lain yang relevan. Analisis data menggunakan teknis descriptive analysis. Hasil pembahasan menunjukkan bahwa kebijakan fiskal di masa Khalifah Umar bin Khattab menggunakan sistem anggaran berimbang (balanced budget) yang dikelolan melalui Baitul Maal. Instrumen kebijakan fiskal yang dikembangkan antara lain zakat, infak, sedekah, wakaf, ghanimah, fa'i, kharaj, jizyah, ushur, dan khums. Sementara dari sisi pengeluaran alokasi anggaran berdasarkan skala prioritas, kemudian digunakan untuk pemenuhan kebutuhan mustahik, pertahanan dan keamanan, sosial dan keagamaan, serta administrasi negara.
\end{abstract}

Keyword: Instrumen Kebijakan Fiskal, Umar bin Khattab, Sejarah Islam, Keuangan Publik. 


\section{Pendahuluan}

Pembangunan ekonomi merupakan pondasi utama dalam mewujudkan kesejahteraan1. Kesejahteraan menjadi tujuan berbagai Negara di belahan dunia. Kesejahteraan akan tercapai, jika perekonomian mencapai stabilitas2. Stabilitas dapat terwujud jika pemerintah mampu mengelola perekonomian secara efektif dan efisien3. Untuk mencapai hal tersebut, dapat dilakukan melalui instrument dalam berbagai kebijakan-kebijakan pemerintah4. Namun demikian, sampai detik ini berbagai sistem yang diformalisasikan di berbagai Negara belum mampu mencapai kesejahteraan 5 . Jika merujuk pada sejarah, terutama pada masa kejayaan Islam, sejarah menunjukkan bahwa peradaban Islam sesungguhnya banyak berkontribusi dalam perkembangan dan kemajuan di bidang ekonomi 6. Salah satunya pada masa Khalifah Umar bin Khattab, yang mana pada saat itu perekonomian mengalami berbagai kemajuan khususnya di bidang ekonomi 7.

Umar bin Khattab dalam mengelola perekonomian negara berlandaskan pada prinsip syariah, yakni berpedoman pada al-Quran dan as-Sunnah. Kebijakan fiskal yang diimplemantasikan Umar bin Khattab bertujuan untuk mencapai kemaslahatan umat. Bahkan pada masa pemerintahannya banyak berkembang instrument kebijakan fiskal. Dengan perkembangan ini menunjukkan bahwa aktivitas perekonomian berjalan sangat baik. Disisi yang lain, hal ini juga menjadi indikasi bahwa kondisi masyarakat pada saat itu tergolong sejahtera. Hal ini disebabkan, di dalam Islam sangat

1 Dian Indah Cahyani and Sumadi Sumadi, "Alternatif Sistem Ekonomi Islam Untuk Indonesia Yang Lebih Sejahtera," Jurnal Ilmiah Ekonomi Islam 1, no. 02 (2017): 88-93, https://doi.org/10.29040/jiei.v1i02.31.

${ }^{2}$ Muslikhati and Imamul Hakim, "Does International Trade Affect Welfare? Economic Fiqh Analysis of Umar Bin Khattab," Jurnal Ekonomi Pembangunan (JEP) 18, no. 01 (2020): 39-50.

3 Suleman Jajuli, "Kebijakan APBN Khalifah Umar Bin Khattab," Al Mashlahah Jurnal Hukum Dan Pranata Sosial Islam 53, no. 9 (2019): 1689-99, https://doi.org/10.1017/CBO9781107415324.004.

4 Aan Jaelani, "Fiscal Policy in Indonesia: Analysis of State Budget 2017 in Islamic Economic Perspective," in SSRN Electronic Journal, 2018, 1-17, https://doi.org/10.2139/ssrn.2881093.

5 Khaerul Aqbar and Azwar Iskandar, "Kontekstualisasi Ekonomi Zakat Dalam Mengentaskan Kemiskinan: Studi Kebijakan Zakat Umar Bin Khattab Dan Perzakatan Di Indonesia," Laa Maisyir 6, no. 2 (2019): 226-45.

${ }^{6}$ Muhammad Fauzan, "Kebijakan Fiskal Dalam Perekonomian Islam Di Masa Khalifah Umar Bin AlKhathab," Human Falah 4, no. 1 (2017): 51-71.

7 Syarifuddin Israil, "Kebijakan Ekonomi Umar Bin Khattab," Jurnal Manajemen Dan Akuntansi 12, no. 1 (2011): 91-98. 
memperhatikan atau bahkan sangat peduli dengan kaum dhuafa 8. Umar bin Khattab dalam hal ini mulai memperkenalkan adanya zakat produktif, dimana para mustahik tidak hanya diberikan dalam bentuk zakat konsumtif tetapi juga didorong untuk memiliki kemandirian ekonomi 9.

Pengelolaan keuangan Negara pada masa sejarah Islam dikelola melalui Baitul Maal 10. Baitul Maal saat itu berwenang dan berfungsi sebagai perbendaharaan Negara 11. Pengelolaan Keuangan Neara juga dikenal dengan istilah Keuangan Publik Islam, didalamnya mengelola sisi penerimaan dan pengeluran berdasarkan prinsip Islam 12. Saat Umar bin Khattab menjadi Khalifah, Baitul Maal resmi sebagai institusi keuangan publik 13. Dari sisi pendapatan, Umar bin Al-Khathab melakukan berbagai inovasi yang belum pernah terjadi pada khalifah sebelumnya. Salah satunya berkaitan dengan kebijakan menetapkan kharaj 14 dan 'usyur 15. Kebijakan fiskal dari sisi penerimaan bersumber dari fa'i dan kharaj 16, pemilikan umum, dan sedekah 17. Kebijakan fiskal

\footnotetext{
${ }^{8}$ Mohammed B Yusoff, "Fiscal Policy in an Islamic Economy and the Role of Zakat," IIUM Journal of Economics and Management 14, no. 2 (2006): 117-45.

9 Siti Aisyah and Nurizal Ismail, "The Distribution of Zakat Ant the Time of Caliph Umar Ibn Khattab," Al-Iktisab: Journal of Islamic Economic Law 3, no. 2 (2019): 132-50, https://doi.org/10.4324/9780429448997-6.

10 Esti Alfiah, "Pemikiran Ekonomi Umar Bin Khaththab Tentang Kebijakan Fiskal," Al-Intaj 3, no. 1 (2017): 54-70.

${ }^{11}$ Hendri Hermawan Adinugraha, "The Economic of Umar Bin Khattāb Policy in Modern Economic Policy," in The First International Conference on Law, Business and Government, 2013, 83-89.

${ }^{12}$ Any Setianingrum, "Desentralisasi Fiskal Kontemporer Dalam Perpektif Kebijakan Publik Islam," Ekonomika-Bisnis Vol.4, no. No. 1 (2013): Hal 1-12; Rusli Siri, M. Wahyudin Abdullah, and Ridwan Tabe, "The Implementation of Fiscal Fiance by Umar Bin Khatb (an Enforcement in Indonesia)," Tasharruf: Journal Economics and Business of Islam 5, no. 1 (2020): 26-45.

${ }^{13}$ Denil Setiawan, "Analisis Zakat Sebagai Instrument Kebijakan Fiskal," Al Amwal 1, no. 2 (2019): 11831.

${ }^{14}$ Muhammad Riza, "Maqashid Syariah Dalam Penerapan Pajak Kharaj Pada Masa Umar Bin Khattab Ra," Jurnal Ekonomi Dan Bisnis Islam 2, no. 2 (2017): 1-14, https://doi.org/10.32505/jebis.v2i2.181.

15 Nurma Sari, "Zakat Sebagai Kebijakan Fiskal Pada Masa Kekhalifah Umar Bin Khattab," Jurnal Perspektif Ekonomi Darussalam 1, no. 2 (2017): 172-84, https://doi.org/10.24815/jped.v1i2.6552; Junaidi Lbs, "Pajak Sebagai Sumber Pendapatan Negara (Analisis Sejarah Penentuan Kadar Pajak Di Masa Umar Bin Khattab Menurut Abu Yusuf Dalam Kitab Al-Kharaj)," Al-Intaj: Jurnal Ekonomi Dan Perbankan Syariah 2, no. 1 (2016): 11-20.

${ }^{16}$ Gustomo Try Budiharjo, "Kebijakan Kharāj Khalifah Umar Ibn Khattāb Gustomo Try Budiharjo," $A z$ Zarqa' 5, no. 2 (2013): 116-44.

${ }^{17}$ Anton Hindarjo, "Analisa Zakat Dan Instrumen Sejenis Terhadap Sistem Fiskal Islam," Jurnal AsySyukriyyah 19, no. 2 (2018): 35-60.
} 
dari sisi pengeluaran adalah untuk menjamin pemenuhan kebutuhan-kebutuhan primer (basic needs) dan pemenuhan kebutuhan sekunder dan tersier. Hal ini dilakukan dalam rangka mewujudkan perekonomian yang stabil baik makro maupun mikro 18 , dan pada akhirnya menciptakan kesejahteraan.

Tujuan artikel ini adalah untuk mengidentifikasi dan mendeskripsikan bagaimana kebijakan fiscal yang diimplementasikan Khalifah Umar bin Khattab, kemudian mengidentifikasi dan mendeskripsikan instrument kebijakan fiscal yang diimplementasikan Khalifah Umar bin Khattab, dan mengidentifikasi dan mendeskripsikan kelebihan Khalifiah Umar bin Khattab dalam menentukan kebijakan fiskal.

\section{Metodologi Penelitian}

Metode artikel ini menggunakan pendekatan kualitatif, dengan menggunakan data sekunder. Data sekunder diperoleh dengan menggunakan pendekatan library research, yaitu dengan melakukan penelusuran berbagai referensi yang mengkaji tentang kebijakan fiscal pada masa Khalifah Umar bin Khattab yang berupa buku, hasil penelitian, data website, dan sumber lainnya yang relevan dengan kajian ini. Teknik analisis data menggunakan pendekatan descriptive analysis, yaitu setelah data dikumpulkan kemudian dideskripsikan, kemudian dianalisis untuk memperoleh jawaban sesuai dengan tujuan artikel ini.

\section{Metode Penelitian}

Penelitian ini bersifat kualitatif dengan bentuk deskriptif analisis. Secara garis besar penelitian ini termasuk dalam jenis penelitian pustaka. Bahan utama atau primer penelitian ini, adalah data yang diambil dari Pengadilan Agama Kota dan Kabupaten Malang terkait penetapan hakim dalam perkara Dispensasi Kawin. Selain data dari Pengadilan Agama, juga menggunakan data dari BKKBN Kota Malang. Sedangkan

${ }^{18}$ Anas Malik, "Analisis Kebijakan Fiskal Masa Khalifah Umar Bin Khatab Dalam Pandangan Ekonomi Modern," Jurnal Al Nidzom 3, no. 2 (2019): 56-69. 
untuk bahan sekunder berasal dari beberapa buku, jurnal, dan penelitian terdahulu. Jurnal dan penelitian tentang dispensasi kawin, dan buku-buku tentang teori fenomologi, yang nantinya akan digunakan untuk rujukan.

Data-data yang telah didapatkan kemudian akan dilakukan analisis menggunakan teori fenomenologi. Data yang terkumpul akan melalui tahapan reduksi, penyajian dan penarikan kesimpulan.

\section{Hasil dan Pembahasan}

\section{Kebijakan Fiskal Khalifah Umar bin Khattab}

Pada masa pra-Islam mayoritas mata pencaharian masyarakat Arab adalah menjadi pedagang, petani, dan pekerja industri. Aktivitas perdagangan menjadi mata pencaharian yang mendominasi, disebabkan letak geografisnya yang menghubungkan Negeri Syam (Yordania, Palestina, dan Libia), Yaman, dan Habasyah (Ethopia) ${ }^{19}$. Sementara itu, kegiatan industri menjadi sector yang paling lemah. Mayoritas kegiatan industri kala itu adalah berprofesi yang umumnya dilakukan oleh para budak dan orang-orang Yahudi. Di antara profesi tersebut, yang sangat menonjol adalah tukang besi, tukang kayu, pertenunan dan pembuatan senjata.

Pada masa sebelum Khalifah Umar bin Khattab, perekonomian umat Islam masih labil dikarenakan banyaknya kekacauan yang terjadi seperti kaum murtad, etnosentrisme (fanatik terhadap sukunya sendiri), dan kelompok yang salah dalam memahami tafsir Al Quran. Namun sejak Umar bin Khattab diangkat menjadi khalifah, perekonomian mulai stabil dan kesejahteraan mulai terlihat. Walaupun pernah mengalami krisis, yaitu krisis tahun ramadah (berdebu) sekitar tahun ke 18 hijriah. Pada saat krisis tersebut, terjadi kekeringan hebat yang mengakibatkan banyak menimbulkan korban, baik manusia, tumbuhan, maupun binatang. Umar bin Khattab mampu meminimalisir kekacauan tersebut dengan melakukan pengetatan konsumsi, pengetatan belanja, membentuk posko pengungsian dan meminta bantuan ke berbagai daerah lain yang berada di bawah kekuasaan Islam. Selain itu, Umar bin Khattab juga mengambil

\footnotetext{
${ }^{19}$ Heriyansyah, "Perjalanan Bisnis Nabi Muhammad SAW," Ad-Deenar: Jurnal Ekonomi Dan Bisnis Islam 2, no. 2 (2018): 190-205, https://doi.org/http://dx.doi.org/10.30868/ad.v2i02.356.
} 
kebijakan pungutan zakat yang longgar dan mengahirkan pungutan zakat, sehingga zakat ditarik pada masa akhir paceklik dan awal musim subur khusus untuk tahun ramadah ini ${ }^{20}$.

Secara umum kebijakan fiskal berfungsi untuk mengelola pendapatan dan mendistribusikannya dalam rangka mewujudkan kesejahteraan negara. Kebijakan fiskal yang berlandaskan Islam yang dilakukan oleh khalifah Umar tidak hanya berfungsi dalam hal tersebut, melainkan sebagai kewajiban negara dalam memenuhi kebutuhan rakyat dan sebagai kewajiban khalifah dalam melayani rakyatnya. Umar bin Khattab sangat ketat dalam mengelola kebijakan fiskal, mulai dari penerimaan sampai pengeluaran, dikelola sedemikian rupa agar penggunaan sesuai dengan ketentuan untuk meminimalisir praktik kecurangan (korupsi). Dengan demikian, akan tercipta administrasi yang transparan, efektif, dan efisien ${ }^{21}$.

Baitul Maal pada masa pemerintahan Umar bin Khattab secara tidak langsung menjadi pelaksana kebijakan fiskal negara Islam, karena lembaga yang mengelola seluruh pendapatan negara. Pada masa Khalifah Umar bin Khattab, Baitul Maal memiliki tempat yang permanen, baik berada di ibu kota negara maupun di setiap ibu kota provinsi. Hal ini dilakukan untuk mempermudah proses pendistribusian anggaran. Pada masa itu, Abdullah bin Irqam dipercaya sebagai menteri keuangan dibantu oleh Abdurrahman bin Ubaid Al-Qori dan Muayqab ${ }^{22}$. Dalam pengelolaannya, Khalifah Umar menetapkan satu tahun anggaran selama 360 hari dan sehari untuk pembersihan Baitul Maal. Jadi di akhir tahun tidak ada harta yang tersisa di Baitul Maal, melainkan terdistribusi secara merata untuk memenuhi kebutuhan rakyat dan sebagai cadangan negara untuk keperluan mendesak.

Dalam hal pengawasan, Khalifah Umar bin Khattab memberi tanggung jawab independensi kepada para wali (kekuasaan eksekutif), yang bersandar pada sistem pemisahan tugas administrasi dan tugas-tugas akuntansi dalam perangkat negara. Di samping melakukan pengawasan, Khalifah Umar juga membentuk sistem administrasi

\footnotetext{
${ }^{20}$ Aqbar and Iskandar, "Kontekstualisasi Ekonomi Zakat Dalam Mengentaskan Kemiskinan: Studi Kebijakan Zakat Umar Bin Khattab Dan Perzakatan Di Indonesia."

${ }^{21}$ Setianingrum, "Desentralisasi Fiskal Kontemporer Dalam Perpektif Kebijakan Publik Islam."

22 Alfiah, "Pemikiran Ekonomi Umar Bin Khaththab Tentang Kebijakan Fiskal."
} 
yang jelas untuk setiap pos-pos pendapatan yang diterima ${ }^{23}$. Hal ini yang menjadi salah satu keunggulan Khalifah Umar dalam menentukan kebijakan, yakni dengan membentuk departemen-departemen khusus, antara lain :

Page $\mathbf{8 7}$ 1. Departemen pelayanan militer untuk mendistribusikan dana kepada orang-orang yang terlibat dalam peperangan.

2. Departemen kehakiman dan eksekutif yang bertanggung jawab menggaji para hakim dan pejabat eksekutif.

3. Departemen pendidikan dan pengembangan Islam untuk mendistribusikan bantuan dana bagi penyebar dan pengembang ajaran Islam beserta keluarganya, seperti guru dan juru dakwah.

4. Departemen jaminan sosial yang bertugas menyimpan daftar bantuan untuk para fakir yang menderita dan miskin.

\section{Instrumen Pendapatan Negara}

Langkah awal yang dilakukan Khalifah Umar bin Khattab dalam mengelola kebijakan fiskal adalah dengan mengklasifikasikan sumber-sumber pendapatan agar jelas pengadministrasiannya ${ }^{24}$. Pengklasifikasian tersebut antara lain :

1. Zakat

Zakat merupakan bagian dari sedekah wajib bagi kaum Muslim yang memiliki harta sesuai ketentuan dan mencapai nisab (zakat mal) serta kewajiban untuk menyucikan harta bagi setiap muslim pada bulan ramadhan (zakat fitrah).

2. Infak, wakaf dan Sedekah

Infak, wakaf dan sedekah merupakan pemberian suka rela masyarakat sebagai wujud tolong-menolong antar sesama untuk kepentingan bersama dengan mengharap ridho Allah.

\footnotetext{
${ }^{23}$ Aqbar and Iskandar, "Kontekstualisasi Ekonomi Zakat Dalam Mengentaskan Kemiskinan: Studi Kebijakan Zakat Umar Bin Khattab Dan Perzakatan Di Indonesia."

${ }^{24}$ Hindarjo, "Analisa Zakat Dan Instrumen Sejenis Terhadap Sistem Fiskal Islam."
} 


\section{Ghanimah (rampasan perang)}

Ghanimah merupakan pendapatan negara yang berasal dari kemenangan (hasil rampasan) perang.

4. Fa'i

Fa'i adalah harta atau tanah milik musuh yang didapat tanpa melalui peperangan.

5. Kharaj (pajak tanah)

Kharaj merupakan tanah yang diperoleh dari orang-orang kafir baik melalui peperangan mupun perjanjian. Baik Muslim maupun nonmuslim yang memanfaatkannya wajib membayar kharaj kepada negara.

6. Jizyah (pajak bagi nonmuslim)

Jizyah merupakan pajak bagi nonmuslim sebagai pengganti zakat fitrah. Jizyah tidak diwajibkan bagi wanita, anak-anak, orang gila, dan nonmuslim yang tidak mampu. Pungutan jizyah ini berakhir jika orang nonmuslim yang bersangkutan telah masuk Islam.

\section{Ushur (bea cukai)}

Ushur merupakan pajak yang dikenakan kepada pedagang kafir harby yang meilntasi daerah perbatasan negara. Pajak ini dikenakan sebagai akibat adanya pungutan cukai yang dikenakan kepada pedagang Muslim yang melintasi daerah perbatasan negara mereka agar terjadi kesetaraan.

8. Khums (pajak rikazh dan barang tambang)

Khums merupakan pajak yang diambil seperlima (20\%) bagian dari barang temuan (rikazh) dan barang tambang. Persentase tersebut dikenakan jika jumlah rikazh sedikit, namun jika jumlah rikazh sangat besar maka kepemilikannya menjadi milik negara untuk dimanfaatkan demi kemakmuran bersama. 


\section{Pengalokasian Belanja Negara}

Sama halnya dengan pendapatan, Khalifah Umar bin Khattab juga membentuk pospos pengeluaran negara secara rinci sesuai dengan pendapatan yang diterima ${ }^{25}$. Page 89 Pengeluaran Baitul Maal, berdasarkan pemasukannya menjadi empat klasifikasi sebagaimana pada Tabel 1.

Tabel 1. Alokasi Belanja Berdasarkan Sumber Penerimaan

\begin{tabular}{|c|c|}
\hline Penerimaan & Pengeluaran \\
\hline Zakat & $\begin{array}{l}\text { Fakir, miskin, amil, mualaf, budak, gharim, fisabilillah, dan } \\
\text { ibnu sabil (8 asnaf) serta proyek umum, seperti rumah } \\
\text { sakit dan sekolah gratis untuk fakir miskin. }\end{array}$ \\
\hline Ghanimah & $\begin{array}{r}\text { Anak yatim, fakir, dan ibnu sabil, dan dimanfaatkan untuk } \\
\text { membeli kendaraan dan peralatan perang. }\end{array}$ \\
\hline Rikazh & $\begin{array}{r}\text { Khusus untuk kemaslahatan kaum fakir seperti proyek } \\
\text { untuk kepentingan umum. }\end{array}$ \\
\hline $\begin{array}{r}\text { Jizyah, } \\
\text { kharaj, fa'i } \\
\text { dan ushur }\end{array}$ & $\begin{array}{l}\text { Gaji para pegawai, pendanaan untuk instansi } \\
\text { pemerintah, dan persediaan dana dalam keadaan } \\
\end{array}$ \\
\hline
\end{tabular}

Sumber: ${ }^{26}$

Untuk pengeluaran di luar zakat, secara lebih terperinci akan dijelaskan sebagai berikut:

1) Ghanimah

Harta ghanimah dapat digunakan untuk hadiah bagi pasukan perang, para wanita perawat tentara, dan untuk membebaskan para tentara Muslim yang ditawan musuh sebelum harta itu dibagikan.Setelah itu sisanya, yaitu 4/5 untuk pasukan yang mengikuti peperangan, $1 / 5$ untuk baitul mal.

\footnotetext{
${ }^{25}$ Sari, "Zakat Sebagai Kebijakan Fiskal Pada Masa Kekhalifah Umar Bin Khattab."

${ }^{26}$ Setiawan (2019)
} 
2) Rikaz

Kekayaan Baitul Maal dapat digunakan untuk membiayai seluruh perangkat kenegaraan dan pembangunan fasilitas umum yang membutuhkan dana besar. Selain itu juga digunakan untuk melakukan persiapan peperangan dan penaklukan terhadap wilayah lain.

3) Jizyah, kharaj, dan ushur

Jizyah, kharaj, dan ushur digunakan untuk pengeluaran anggaran rutin yaitu :

a. Gaji kepala negara

Pada masa kekhalifahan Umar bin Khattab, para sahabat menetapkan tunjangan sebesar 16.000 dirham setahun, selain tunjangan bahan makanan dan daging kambing untuk khalifah Umar dan keluarganya. Pada awalnya, tunjangan ini kelihatan melebihi kebutuhannya, tetapi ternyata khalifah Umar pernah berhutang ke baitul mal karena tunjangan yang diterimanya tidak mencukupi kebutuhannya dan keluarganya.

b. Gaji pegawai

Khalifah Umar menetapkan imbalan para pegawai sebagaimana pada Tabel 2.

\section{Tabel 2. Alokasi Belanja Gaji Pegawai}

\begin{tabular}{|l|l|}
\hline Pegawai & \multicolumn{1}{|c|}{ Tunjangan } \\
\hline Bashrah & $\begin{array}{l}\text { Jatah harian berupa dua ekor kambing dan dua } \\
\text { buah ember yang dipotong dan dimasak pagi } \\
\text { dan sore, sementara kuahnya dijadikan minuman. }\end{array}$ \\
\hline Kepala Daerah & $\begin{array}{l}\text { Tunjangan 600 dirham/hari, setengah daging } \\
\text { domba, kepala, kulit, dan kakinya serta setengah } \\
\text { ember makanan. }\end{array}$ \\
\hline
\end{tabular}




\begin{tabular}{|l|l|}
\hline $\begin{array}{l}\text { Imam sholat, pengurus } \\
\text { tanah, dan penanggung } \\
\text { jawab baitul mal }\end{array}$ & $\begin{array}{l}\text { Satu ekor kambing setiap hari dengan rincian 1/5 } \\
\text { bagian untuk imam sholat dan masing-masing } 1 / 4 \\
\text { bagian untuk pengurus tanah, dan penanggung } \\
\text { jawab baitul mal. }\end{array}$ \\
\hline
\end{tabular}

c. Tunjangan bagi tentara dan veteran

Khalifah Umar bin Khattab memberikan tunjangan kesejahteraan yang berkala tahunan terhadap para veteran perang, anak-anak, dan janda-janda yang ditinggal mati para suami mereka. Dengan cara mendata seluruh penduduk melalui sebuah lembaga pemerintahan khusus, tanpa membedakan asal dan keturunan. Bagi bayi yang lahir dalam keadaan Islam mendapatkan tunjangan 100 dirham. Ketika sudah merangkak ditambah menjadi 200 dirham. Ketika mendekati baligh ditambah lagi menjadi 500 atau 600 dirham. Tunjangan yang diberikan tidak hanya berupa uang, tetapi juga bahan makanan dan keperluan laian. Berupa uang dibagikan dua tahun sekali, sedangkan bahan makanan dibagikan sebulan sekali. Rincian pengeluaran baitul mal untuk pasukan dan veteran dapat dilihat dalam Tabel 3.

Tabel 3. Rincian Pengeluaran Baitul Mal untuk Pasukan

\begin{tabular}{|r|r|r|lr|}
\hline No & Jumlah & Penerima & Keterangan \\
\hline 1. & Pemberian & Bagi setiap istri Rasul & $\begin{array}{l}\text { Awalnya Shafiyah dan } \\
\text { Juwairiyah menerima 6000, } \\
\text { tetapi setelah keduanya } \\
\text { protes, akhirnya mereka } \\
\text { disamakan dengan yang lain. }\end{array}$ \\
\hline 2. & 12.000 dirham & Abbas bin Abdul Muthalib & \\
\hline 3. & 5.000 dirham & $\begin{array}{l}\text { Kaum Muhajirin dan } \\
\text { Anshar yang mengikuti } \\
\text { perang badar }\end{array}$ & Dalam riwayat lain disebutkan \\
\hline 4. & 5.000 dirham & $\begin{array}{r}\text { Hasan dan Husein masuk } \\
\text { dalam kerabat Rasul }\end{array}$ & \\
\hline
\end{tabular}




\begin{tabular}{|c|c|c|c|}
\hline 5. & 4.000 dirham & $\begin{array}{l}\text { Orang yang Islamnya } \\
\text { seperti pejuang Badar, } \\
\text { tetapi tidak ikut perang } \\
\\
\\
\text { Badar. }\end{array}$ & $\begin{array}{r}\text { Utsman bin Zaid dimasukkan } \\
\text { dalam daftar mereka }\end{array}$ \\
\hline 6 & 4.000 dirham & $\begin{array}{r}\text { Umat Islam yang ikut hijrah } \\
\text { ke Habsyah }\end{array}$ & \\
\hline 7. & 4.000 dirham & Kaum Anshar & \\
\hline 8. & 4.000 dirham & Usamah bin Zaid & $\begin{array}{l}\text { Karena posisinya dan ayahnya } \\
\text { lebih disayangi Rasul } \\
\\
\text { dibanding Ibn Umar. }\end{array}$ \\
\hline 9. & 4.000 dirham & Umar bin Abi Salamah & $\begin{array}{r}\text { Dalam riwayat lain : } 3.000 \\
\text { dirham. Dia dilebihkan, karena } \\
\text { posisi ibunya yang terhormat } \\
\text { dalam Islam. }\end{array}$ \\
\hline 10. & 2.000 dirham & Abdullah bin Umar & \\
\hline 11. & 2.000 dirham & Nadhar bin Anas & $\begin{array}{l}\text { la dimuliakan, karena } \\
\text { keutamaan Anas dalam } \\
\text { perang Uhud, saat semua } \\
\text { orang menyangka Rasul telah } \\
\text { meninggal, ia maju dan syahid } \\
\text { dengan gagah. }\end{array}$ \\
\hline 12 & 2.000 dirham & Al-Mirqah & $\begin{array}{r}\text { Namanya diperkirakan : } \\
\text { Hasyim bin Utbah bin Abi } \\
\text { Waqash. }\end{array}$ \\
\hline 13. & 2.000 dirham & $\begin{array}{r}\text { Istri kaum Muhajirin dan } \\
\text { Anshar }\end{array}$ & \\
\hline 14. & 2.000 dirham & $\begin{array}{r}\text { Putra kaum Muhajirin dan } \\
\text { Anshar }\end{array}$ & $\begin{array}{l}\text { Abu Salamah diberi } 3.000 \\
\text { dirham, karena keutamaan } \\
\\
\text { istrinya dalam Islam. }\end{array}$ \\
\hline 15. & 800 dirham & $\begin{array}{r}\text { Penduduk Mekkah dan } \\
\text { masyarakat luas }\end{array}$ & $\begin{array}{r}\text { Riwayat lain : antara } 300 \text { dan } \\
400 \text { dirham }\end{array}$ \\
\hline 16. & $\begin{array}{l}\text { 600, 400, 300, } \\
\text { dan } 200 \text { dirham }\end{array}$ & $\begin{array}{rr}\text { Untuk } & \text { perempuan } \\
\text { Muhajirin dan Anshar }\end{array}$ & \\
\hline
\end{tabular}

Sumber: 27

${ }^{27}$ Alfiah (2017) 
Khalifah Umar bin Khattab mengalokasikannya ke dalam 14 bagian ${ }^{28}$, yaitu:

1. Belanja kebutuhan operasional pemerintah (dar al-khalifah) termasuk upacara kemerdekaan.

2. Belanja penunjang wilayah (masalih ad-daulah) termasuk kebutuhan administrasi surat-menyurat.

3. Biaya pembangunan kota Bashrah dan Kufah.

4. Pergantian mata uang (biaya moneter).

5. Belanja pegawai negara.

6. Biaya utang tanggungan negara.

7. Belanja umum yang berkaitan dengan infrastruktur.

8. Biaya fasilitas kehakiman.

9. Biaya santunan kepada kerabat Rasul dan lain-lain.

10. Belanja jihad (militer, persenjataan, dan lain-lain.

11. Biaya perluasan Masjidil Haram dan kelambu Kiswah, serta lampu penerangan masjid.

12. Biaya penyimpanan harta zakat.

13. Biaya penjagaan dan penyimpanan harta umum.

14. Biaya pengurus urusan darurat (at-Tawary).

Untuk memprioritaskan pengeluaran secara efektif, Khalifah Umar bin Khattab juga membagi biaya kemasyarakatan menjadi dua sebagaimana tampak pada Tabel 4.

\section{Tabel 4. Prioritas Pengeluaran Baitu Mal}

\begin{tabular}{|c|c|c|c|}
\hline \multicolumn{2}{|c|}{ Primer } & \multicolumn{2}{|c|}{ Sekunder } \\
\hline Biaya pertahanan & - & Beasiswa yang belajar ke Madinah & - \\
\hline Penyaluran Ushur kepada mustahik & - & Hiburan untuk delegasi asing, biaya & - \\
\hline Membayar gaji pegawai, guru, imam, & • & perjalanan & \\
\hline qadhi, muadzin, dan pejabat negara & & Membayar denda atas mereka yang & • \\
\hline Infrastruktur & $\bullet$ & mati terbunuh secara tidak sengaja & \\
\hline Biaya fasilitas kehakiman & - & oleh pasukan Islam & \\
\hline Biaya pencetakan dirham baru & • & & \\
\hline
\end{tabular}

\footnotetext{
${ }^{28}$ Israil, "Kebijakan Ekonomi Umar Bin Khattab."
} 


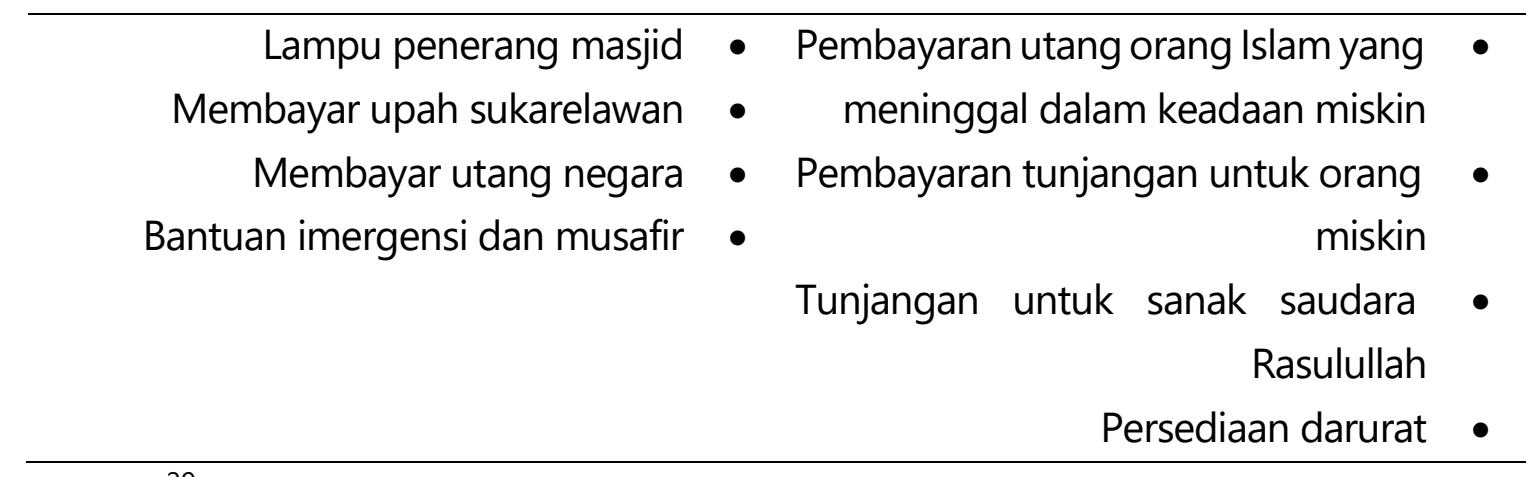

Source: ${ }^{29}$

\section{Keberhasilan Kebijakan-Kebijakan Khalifah Umar Bin Khattab}

Berdasarkan pembahasan sebelumnya tentang kebijakan-kebijakan khalifah Umar bin Khattab, ada beberapa kebijakan yang menjadi terobosan baru dan inovasi dalam pemerintahan Islam yang belum ada pada masa khalifah sebelumnya. Hal ini selain menjadi ciri khas dan kelebihan khalifah Umar bin Khattab dalam memajukan sector ekonomi. Kemajuan dibidang ekonomi tersebut terutama ditandai dengan adanya pemerataan kesejahteraan rakyat dan peningkatan perokonomian negara. ${ }^{30}$ Adapun terobosan dalam hal kebijakan antara lain adanya pembentukan departemendepartemen pengelola, menyisakan cadangan kas di Baitul Maal, membatalakan zakat untuk muallaf, memberikan zakat dua kali lipat kepada mustahik, pemberian zakat konsumtif dan produktif, serta program jaminan social.

Dalam membentuk departemen-departemen pengelola, menjadi salah satu kebijakan yang membuat pemerintahan khalifah Umar bin Khattab berhasil. Dengan adanya departemen-departemen khusus yang dikepalai oleh pejabat-pejabat amanah dan administrasi pengelolaan keuangan yang jelas menjadikan perekonomian negara maju pesat dan kebijakan fiskal sukses menstabilkan ekonomi masyarakat. Dalam hal menyisakan harta Baitul Maal sebagai cadangan, juga belum pernah dilakukan oleh khalifah sebelumnya, bahkan Rasul tida pernah mengajarkannya. Tetapi khalifah Umar memiliki pandangan futuristic bahwa sebuah negara membutuhkan dana cadangan

\footnotetext{
${ }^{29}$ Israil (2011)

30 Khoirul Anwar et al., "Ka'b Al-Ahbar: Founder of the Transformation Jewish Tradition to Islam," 2021, 17-19, https://doi.org/10.4108/eai.14-10-2020.2303851.
} 
sebagai antisipasi adanya kebutuhan yang mendesak. Kebijakan ini juga berfungsi ketika terjadi krisis kekeringan hebat (ramadah) di mana banyak tumbuhan dan hewan mati, yang menyebabkan krisis air dan kelaparan.

Dalam hal membatalkan zakat untuk muallaf. Pembatalan zakat ini tidak semenamena khalifah Umar lakukan, melainkan pandangannya bahwa muallaf yang dirasa sudah cukup kuat iman Islamnya tidak perlu lagi menerima zakat. Kemudian dana zakat tersebut bisa dialihkan kepada yang lebih membutuhkan, yakni fakir miskin. Dalam memungut zakat kepada muzakki dan membayar zakat kepada mustahik dua kali lipat. Pemungutan dan pembayaran zakat dua kali lipat ini dimaksudkan untuk para muzakki dan mustahik yang belum membayar dan menerima zakat di tahun sebelumnya, maka wajib membayar dan menerima zakat dua kali lipat di tahun berikutnya.

Dalam hal Pemberian zakat konsumtif. Kebijakan khalifah Umar dalam pemberian zakat konsumtif bagi setiap fakir adalah pemberian satu ekor unta penuh dengan muatan kebutuhan pokok. Tidak hanya memberikan zakat konsumtif, khalifah Umar juga memberikan zakat produktif kepada orang-orang seorang miskin dengan tujuan mendorong masyarakat untuk lebih mandiri, yakni dengan memberikan satu ekor anak unta beserta dua induknya agar bisa diternakkan. Dalam hal mengadakan program jaminan sosial, dimana program ini dikhususkan untuk para fakir miskin, yakni dengan memberikan tunjangan dan tambahan pensiun.

Keberhasilan khalifah Umar bin Khattab di atas, tidak lepas dari kecerdasannya dalam memanajemen segala urusan negara dan kepatuhannya terhadap Allah, yakni dengan selalu menjadikan al-Quran dan as-Sunnah sebagai landasan dalam memutuskan ijtihadnya. Faktor-faktor lain yang mendukung keberhasilannya adalah instrumen fiskal yang diterapkan khalifah Umar, yaitu: (1) Peningkatan pendapatan dan partisipasi kerja, dimana Khalifah Umar selalu memantau pendapatan dan hak-hak pada Baitul Maal, dan selalu memantau tanah-tanah garapan agar tidak ada yang terbengkalai. Jadi pengawasan adalah hal yang penting bagi khalifah Umar untuk memastikan apakah kebijakannya berjalan sesuai dengan tujuan. (2) Pemungutan pajak, kebijakan ini berhasil menciptakan stabilitas harga dan mengurangi inflasi. Pada saat stagnasi, menurunnya permintaan dan penawaran agregat, pemerintah dapat mendorongnya dengan pajak khums. Dengan kebijakan ini, harga tetap stabil dan produksi tetap 
berjalan. (3). Pengaturan anggaran yang cermat dan proporsional menjaga keseimbangan tidak akan terjadi defisit anggaran bahkan menjadi surplus.

\section{Simpulan}

Berdsarkan hasil analisis pembahasan menunjukkan bahwa kebijakan fiskal di masa Khalifah Umar bin Khattab menggunakan sistem anggaran berimbang (balanced budget) yang dikelolan melalui Baitul Maal. Instrumen kebijakan fiskal yang dikembangkan antara lain zakat, infak, sedekah, wakaf, ghanimah, fa'i, kharaj, jizyah, ushur, dan khums. Sementara itu, dari sisi pengeluaran alokasi anggaran berdasarkan skala prioritas, kemudian digunakan untuk pemenuhan kebutuhan mustahik, pertahanan dan keamanan, sosial dan keagamaan, serta administrasi negara. Kelebihan Khalifah Umar bin Khattab adalah adanya berbagai terobosan dalam hal kebijakan fiscal, antara lain adanya pembentukan departemen-departemen pengelola, menyisakan cadangan kas di Baitul Maal, membatalakan zakat untuk muallaf, memberikan zakat dua kali lipat kepada mustahik, pemberian zakat konsumtif dan produktif, serta program jaminan social.

\section{Daftar Pustaka}

Adinugraha, Hendri Hermawan. "The Economic of Umar Bin Khattāb Policy in Modern Economic Policy." In The First International Conference on Law, Business and Government, 83-89, 2013.

Aisyah, Siti, and Nurizal Ismail. "The Distribution of Zakat Ant the Time of Caliph Umar Ibn Khattab." Al-Iktisab: Journal of Islamic Economic Law 3, no. 2 (2019): 132-50. https://doi.org/10.4324/9780429448997-6.

Alfiah, Esti. "Pemikiran Ekonomi Umar Bin Khaththab Tentang Kebijakan Fiskal." AlIntaj 3, no. 1 (2017): 54-70.

Anwar, Khoirul, Abu Hapsin, Nazar Nurdin, Ubbadul Adzkiya, Iman Fadhilah, and Tedi Kholiludin. "Ka'b Al-Ahbar: Founder of the Transformation Jewish Tradition to Islam," 2021, 17-19. https://doi.org/10.4108/eai.14-10-2020.2303851.

Aqbar, Khaerul, and Azwar Iskandar. "Kontekstualisasi Ekonomi Zakat Dalam Mengentaskan Kemiskinan: Studi Kebijakan Zakat Umar Bin Khattab Dan 
Perzakatan Di Indonesia." Laa Maisyir 6, no. 2 (2019): 226-45.

Budiharjo, Gustomo Try. "Kebijakan Kharāj Khalifah Umar Ibn Khattāb Gustomo Try Budiharjo." Az Zarqa' 5, no. 2 (2013): 116-44.

Page | 97 Cahyani, Dian Indah, and Sumadi Sumadi. "Alternatif Sistem Ekonomi Islam Untuk Indonesia Yang Lebih Sejahtera." Jurnal Ilmiah Ekonomi Islam 1, no. 02 (2017): 88-93. https://doi.org/10.29040/jiei.v1i02.31.

Fauzan, Muhammad. "Kebijakan Fiskal Dalam Perekonomian Islam Di Masa Khalifah Umar Bin Al-Khathab." Human Falah 4, no. 1 (2017): 51-71.

Heriyansyah. "Perjalanan Bisnis Nabi Muhammad SAW." Ad-Deenar: Jurnal Ekonomi Dan Bisnis Islam 2, no. 2 (2018): 190-205.

https://doi.org/http://dx.doi.org/10.30868/ad.v2i02.356.

Hindarjo, Anton. "Analisa Zakat Dan Instrumen Sejenis Terhadap Sistem Fiskal Islam." Jurnal Asy-Syukriyyah 19, no. 2 (2018): 35-60.

Israil, Syarifuddin. "Kebijakan Ekonomi Umar Bin Khattab." Jurnal Manajemen Dan Akuntansi 12, no. 1 (2011): 91-98.

Jaelani, Aan. "Fiscal Policy in Indonesia: Analysis of State Budget 2017 in Islamic Economic Perspective." In SSRN Electronic Journal, 1-17, 2018. https://doi.org/10.2139/ssrn.2881093.

Jajuli, Suleman. "Kebijakan APBN Khalifah Umar Bin Khattab." Al Mashlahah Jurnal Hukum Dan Pranata Sosial Islam 53, no. 9 (2019): 1689-99. https://doi.org/10.1017/CBO9781107415324.004.

Lbs, Junaidi. "Pajak Sebagai Sumber Pendapatan Negara (Analisis Sejarah Penentuan Kadar Pajak Di Masa Umar Bin Khattab Menurut Abu Yusuf Dalam Kitab AlKharaj)." Al-Intaj: Jurnal Ekonomi Dan Perbankan Syariah 2, no. 1 (2016): 11-20.

Malik, Anas. "Analisis Kebijakan Fiskal Masa Khalifah Umar Bin Khatab Dalam Pandangan Ekonomi Modern." Jurnal Al Nidzom 3, no. 2 (2019): 56-69.

Muslikhati, and Imamul Hakim. "Does International Trade Affect Welfare? Economic Figh Analysis of Umar Bin Khattab." Jurnal Ekonomi Pembangunan (JEP) 18, no. 01 (2020): 39-50.

Riza, Muhammad. "Maqashid Syariah Dalam Penerapan Pajak Kharaj Pada Masa Umar Bin Khattab Ra." Jurnal Ekonomi Dan Bisnis Islam 2, no. 2 (2017): 1-14. https://doi.org/10.32505/jebis.v2i2.181.

Sari, Nurma. "Zakat Sebagai Kebijakan Fiskal Pada Masa Kekhalifah Umar Bin Khattab." Jurnal Perspektif Ekonomi Darussalam 1, no. 2 (2017): 172-84. 
https://doi.org/10.24815/jped.v1i2.6552.

Setianingrum, Any. "Desentralisasi Fiskal Kontemporer Dalam Perpektif Kebijakan Publik Islam." Ekonomika-Bisnis Vol.4, no. No. 1 (2013): Hal 1-12.

Setiawan, Denil. "Analisis Zakat Sebagai Instrument Kebijakan Fiskal." Al Amwal 1, no. 2 (2019): 118-31.

Siri, Rusli, M. Wahyudin Abdullah, and Ridwan Tabe. "The Implementation of Fiscal Fiance by Umar Bin Khatb (an Enforcement in Indonesia)." Tasharruf: Journal Economics and Business of Islam 5, no. 1 (2020): 26-45.

Yusoff, Mohammed B. "Fiscal Policy in an Islamic Economy and the Role of Zakat." IIUM Journal of Economics and Management 14, no. 2 (2006): 117-45. 